\title{
Quantifying Factors Affecting Satisfaction of People to Waste Classification at Source: The Case of Hai Chau District, Da Nang
}

\author{
Nguyen Van Thanh, Dang Thanh Le, and Luong Tinh
}

\begin{abstract}
This research assesses the satisfaction of people to the urban waste classification at source as an effective waste management method. There was a survey via google form that was sent to emails of 450 people in Hai Chau District, Da Nang city, from July $2^{\text {th }}, 2021$ to August $5^{\text {th }}, 2021$. Using the structural equation modeling (SEM), the study showed that the facilities of waste classification, expectations of residents, service quality, and perceived value were all statistically significant. In addition, this study also found that it is the responsibility of the local government that has been demonstrated over the years, from paying attention to waste treatment and investing in physical facilities to being at the forefront of different movements of categorizing plastic waste, has created more trust, satisfaction, and support of the people to the movements proposed by the city. The results also show that, when the community is satisfied with the garbage classifying activity, it will create enthusiasm, active participation, and social interaction - community cohesion in the waste classification. The research provides additional evidence on the satisfaction of people to the movement of waste classification at source in Hai Chau district. The study also contributes a part theoretically and provides some implications for managers, citizens, and further researches.
\end{abstract}

Index Terms-Satisfaction, classification, waste, at source, people, Da Nang.

\section{INTRODUCTION}

Waste generated by population growth, urban development, industry, tourism, healthcare, and other activities has been and is exacerbated by environmental pollution and human health. Therefore, waste management is one of the important issues that governments are facing, especially in developing countries. In particular, waste classification and recycling at the source are necessary to condition to reduce waste sources. However, it is reported that more than half of all solid waste is recyclable, but what is interesting is that a large amount of that waste is dumped in the trash [1]. Therefore, people play an important role in waste management factors such as waste generation, source classification, storage, collection, recycling, and treatment [2]. It is estimated that each year in Da Nang city, the amount of plastic waste is disposed to the environment averages

Manuscript received October 13, 2021; revised December 24, 2021.

Nguyen Van Thanh is with Central Theoretical Council of the Communist Party of Vietnam, Vietnam (e-mail:thanhnv1957@gmail.com).

Dang Thanh Le is with National Academy of Public Administration, Vietnam (e-mail: dangthanhle69@gmail.com).

Luong Tinh is with Institute of Social Sciences of the Central Region, Vietnam Academy of Social Sciences, Vietnam (e-mail: luongtinhhoian@gmail.com).
80,000 tons/year, equivalent to $0.19 \mathrm{~kg} /$ day per capita Households in private apartments and condominiums discharge up to 11,198 tons/year of plastic bags, 4,587 tons/year of plastic films, 800 tons/year of plastic beverage bottles, 700 tons/year of plastic foam. Although the city tries to collect domestic waste, including plastic waste, the volume of plastic waste indiscriminately discharged into the environment is about 3,218 tons/year, equivalent to $8 \mathrm{~g} /$ person/day. There is $85 \%$ of plastic waste dumped in Khanh Son landfill site with only $6.2 \%$ of the plastic is categorized to recycle, $8 \%$ of the plastic waste is not controlled that could damage the environment and eco-system [3]. It is predicted that by 2025 , the total amount of domestic solid waste will be 691,624 tons, by 2030 this figure will be 1,096,128 tons. Without effective solutions in classification and treatment, the city will become a challenge. Previous studies have suggested that the classification of waste at source will play an important role in the circular economy while also solving the problem of limited energy supply and environmental protection [4]. The Satisfaction of people is a prerequisite for the implementation and renewal of household solid waste treatment plans in the future[5]. Therefore, improving resident satisfaction is a primary concern of waste management[6], [7].

We have found many models and empirical studies for this topic such as Wang et al. (2020) [8], Abas et al. (2021) [9]; Odonkor et al. (2020) [10], and Fetene (2018) [11]. Since 2017, Da Nang city has piloted the movement of waste sorting at the source in Hai Chau district, but so far no research has been carried out to assess the satisfaction of people with the above operation. According to Cohen et al. (2020) [12], government accountability affects citizen satisfaction. In addition, when people feel satisfied with the activities proposed by the government, it also allows them to connect through information exchange, sharing help, or joint action toward the community's purpose. Therefore, this study will add elements of government responsibility and community cohesion to the research model. The analysis results will suggest governance implications for stakeholders in further improving people's satisfaction with the movement of waste classification at source to aiming to an environmental city.

\section{ANALYTICAL FRAMEWORK AND RESEARCH HYPOTHESIS}

There are many well-known satisfaction models: Oliver's (1980) [13] "Expectations - Perceptions" model, American customer satisfaction index model (ACSI, 1992), European 
customer satisfaction index model (ECSI, 1998) or Dabholkar's (2000) [14] "Antecedent and mediator model". These theoretical models integrate theories of satisfaction and commitment. The model of people's satisfaction as shown in Fig. 1, describes the relationship between the variables: Resident's expectations; Quality service; Perceived value; Facilities for classifying domestic waste; Governmental responsibility; Enthusiasm; Social interaction and community cohesion; Engage actively with Satisfaction.

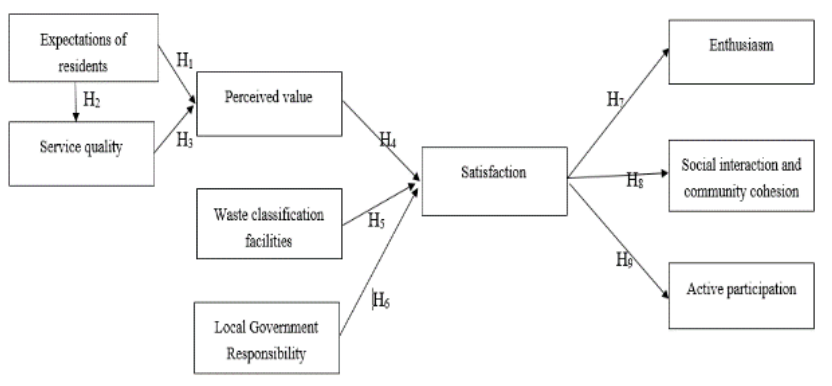

Fig. 1. Proposed research model.

People's expectations are a type of pre-performed belief about a good or service [15]. The quality of waste classification service at source refers to the frequency of collection, the time of garbage collection, and the arrangement of the garbage bins [16], [17]. The quality of waste treatment services in the community has to meet people's expectations [8]-[10]. According to previous studies, it can be hypothesized as follows:

Hypothesis 1: Residents' expectations can improve the service quality of household waste classification at the source.

Consumer expectations are the premise of perceived value [18]. Consumer expectation positively influences perceived value, and perceived value can positively influence satisfaction [8]. People expect garbage sorting facilities or the quality of waste treatment services at the source to have an impact on the perception that waste classification can reduce environmental pollution and that is a very practical activity. Therefore, the following hypothesis can be:

Hypothesis 2: Residents' expectations can enhance the perceived value of household waste classification at the source.

Perceived value is related to quality and satisfaction [19]. Perceived value has a positive influence on customer satisfaction [20], [21]. According to previous studies, it can be hypothesized as follows:

Hypothesis 3: The perceived value of household segregation of waste at source increases with service quality.

Perceived value is considered as the main factor determining customer satisfaction [20], [21]. Ziethaml (1988) [22] suggested that customer satisfaction can be measured by feedback on the customer's experience. It is the customer's perception of a product's economic and/or emotional value resulting from the experience of making the customer happy or unhappy. According to previous studies, it can be hypothesized as follows:

Hypothesis 4: If the perceived value increases, the satisfaction of household waste classification at the source also increases.
Döberl et al. (2002) [23] and Khan et al. (2012) [24] suggested that the level of government investment in waste treatment significantly affects people's satisfaction with the implementation of household waste treatment. Koo et al. (2009) [25] and Chu et al. (2021) [17] showed that the arrangement and deployment of garbage bins and other waste treatment facilities also affects residents' satisfaction with waste management efficiency. Hence, the following hypothesis is proposed:

Hypothesis 5: Satisfaction with household waste separation at source increases if waste classification facilities increase.

According to Cohen et al. (2020) [12], the responsibility of the government affects the satisfaction of citizens, because the more responsible the government is in managing waste in general and waste in particular, the more satisfied people will feel. Hence, the following hypothesis is proposed:

Hypothesis 6: The satisfaction level of the household's garbage classification increases if the responsibility of the local government increases.

If the household is satisfied with the classification and collection of waste at the source of the local government, they will respond and ask family members to perform the act of classifying garbage. Wang et al. (2020) [8] also suggested that once the community is satisfied with the waste classification activity, or with the environmental results, the community will be enthusiastic about the waste classification. Hence, the following hypothesis is proposed:

Hypothesis 7: Satisfaction enhances household enthusiasm for waste classification at the source.

Social interaction is the process of performing social actions between two or more individuals [26]. It represents purposeful, conscious action for a certain value [27]. At the same time, if the household is satisfied with the garbage classification, they will participate more, from there, they have the opportunity to friendly interact and sometimes also receive a lot of help and support from their neighbors when they are in trouble. Hence, the following hypothesis is proposed:

Hypothesis 8: Satisfaction enhances social interaction and community cohesion in household waste classification at the source.

Vivek et al. (2014) [28] defined active participation as one's enthusiastic reactions and emotions". In another word, satisfaction can improve people's active participation. That is, the higher the satisfaction, the more people will participate in waste classifying activities. Hence, the following hypothesis is proposed:

Hypothesis 9: Satisfaction improves the household's active participation in waste classification at the source.

\section{Method AND DATA}

\section{A. Methodology}

To assess the satisfaction of people with the movement of waste classification at source in Hai Chau District, Da Nang, this study applies two main methods: qualitative and quantitative.

Regarding qualitative research method: Firstly, the 
research team reviews relevant documents to identify influencing factors as well as research gaps, then, builds a preliminary questionnaire to conduct a trial survey. In the trial survey, 12 residents are living in the Hai Chau district. In addition, the team also surveyed these residents to find out more factors affecting the satisfaction of people from waste classification at the source. In addition to the comments expressed: expectations, service quality, waste-collecting facilities, collection time, and staff attitude ... the comments also focused on the responsibility of the government expressed through the ideas, such as the responsibility to build and complete the entire management agency of environmental waste, invest in physical means or take the lead in the movement of categorizing plastic waste such as saying no to plastic bottles. Moreover, the comments also show that when people feel satisfied with the activities proposed by the government, it also allows them to bond with each other through information exchange, conversation, being more friendly, or helping each other for the benefit of the community. These activities will be carried out in July 2021, due to the COVID-19 epidemic, the research team sent the questionnaire via email and exchanged it by phone.

Regarding quantitative research: The study uses structural equation modeling (SEM) through SPSS 20 and AMOS 20 software to test and evaluate the satisfaction of people from the movement of waste classification at source in Hai Chau District, Da Nang.

\section{B. Data Collection Methods}

We use the questionnaire survey method through Google form and sent to email and Zalo application of people from July $20^{\text {th }}$ to August $5^{\text {th }}, 2021$. The measurement model includes 42 observed variables, according to [29] the required sample size is $n=210(42 \times 5)$. To achieve the set sample size, there were 450 questionnaires sent via email and Zalo application of people in Da Nang city. There were 420 responses, accounting for $93.33 \%$. All observations used a 5-point Likert scale, ranging from (1) 'strongly disagree' to (5) 'strongly agree'.

\section{Analytical Methods}

Collected data will be evaluated the reliability of each component by using Cronbach's Alpha reliability coefficient tool. Next, using exploratory factor analysis (EFA) for the above reliable observed variables to discover the scale structure of the influential components to assess the satisfaction of people from the movement of waste classification at source in Hai Chau District, Da Nang. When analyzing EFA, the authors used the Principal axis factoring extraction method with Promax rotation and breakpoints when extracting factors with an eigenvalue greater than 1 . Next, the study used confirmatory factor analysis (CFA) to check the reliability and validity of the measurement model. The model is considered to be suitable for the data when indexes such as Chi-squared adjusted for degrees of freedom $(\mathrm{CMIN} / \mathrm{df}) \leq 2$; RMSEA $<0.08$; TLI, CFI $\geq 0.9$ [30]. Finally, the study uses a structural equation model (SEM) to test and measure the factors affecting people's satisfaction with the movement of waste classification at the source in Hai Chau District, Danang.

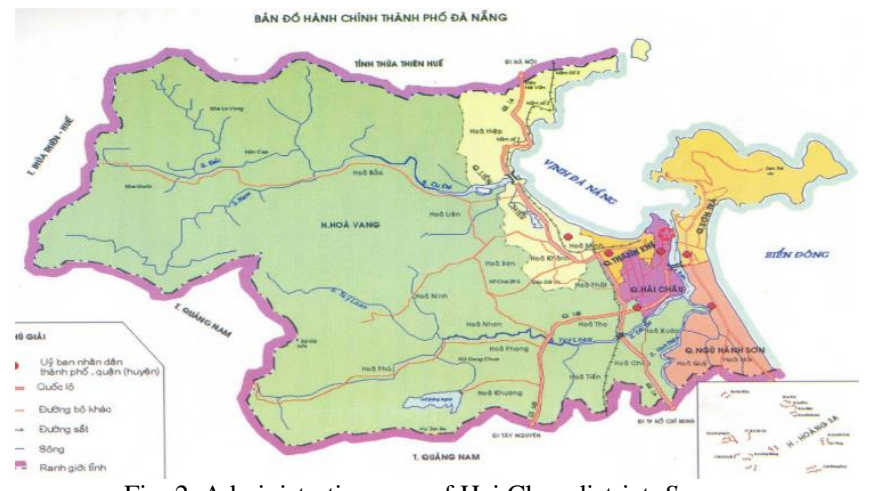

Fig. 2. Administrative map of Hai Chau district. Source: http://danang.ban-do.net/2018/01/quan-hai-chau.html.

\section{RESUlts}

This study tries to explain the satisfaction of people with the movement of waste classification at source in Hai Chau district based on the integration of satisfaction theories from many previous models and studies Wang et al. (2020) [8], Abas et al. (2021) [9]; Odonkor et al. (2020) [10], and Fetene (2018) [11]. However, the fact is that the responsibility of the government affects the satisfaction of the citizens, or when these people are satisfied with the activities proposed by the government, they have the opportunity to bond with each other through information exchange, mutual help, or joint action toward the community's purpose has not been mentioned in this model. Therefore, the present study provides new evidence on the satisfaction of people from the movement of waste classification at source in Hai Chau district, and at the same time contributes a theory part and provides some implications for managers, citizens, and further research in the future.

The survey results obtained 420 responses, accounting for $93.33 \%$, the sample size satisfied the size condition [29]. Among the 420 questionnaires, there were 287 females accounted for $68.3 \%$, and 133 males accounted for $31.7 \%$. In terms of age: there were 57 people under 25 , accounting for $13.6 \%, 185$ people from $25-45$, accounting for $44 \%, 178$ people over 45 , accounting for $42.4 \%$. Regarding educational level: there were 73 people under 5 th grade, accounting for $17.4 \%, 124$ people from grades 6 to 9 , accounting for $29.5 \%$, 134 people from grades 10 to 12 , accounting for $31.9 \%$, and 89 people over 12 , accounting for $21.2 \%$.

\section{A. Preliminary Assessment of the Scale by Cronbach Alpha}

To quantify the factors affecting the satisfaction of people from the movement of waste classification at source in Hai Chau District, Da Nang, the study carried out several steps as follows:

Cronbach's Alpha reliability coefficient is often used to measure how closely the items in the scale are correlated with each other and requires at least three measurement variables. The study carries out testing of each component before analyzing factors. Variables with variable correlation coefficient - sum $<0.3$ will be excluded. Criteria for choosing a scale with reliability Cronbach's Alpha is of 0.6 or higher [31]

The results of running Cronbach's Alpha of 9 factors affecting the satisfaction of people are presented in Table I 
below:

TABLE I: THE RESULTS OF TESTING THE RELIABILITY OF THE SCALE

\begin{tabular}{|l|c|c|}
\hline \multicolumn{1}{|c|}{ Scale } & $\begin{array}{c}\text { Cronbach's } \\
\text { Alpha }\end{array}$ & $\begin{array}{c}\text { Remaining } \\
\text { observations }\end{array}$ \\
\hline 1. Expectation of residents & 0.89 & 4 \\
\hline 2. Quality of service & 0.897 & 4 \\
\hline 3. Perceived value & 0.898 & 4 \\
\hline 4. Waste classification facility & 0.918 & 5 \\
\hline 5. Responsibility of the local government & 0.923 & 5 \\
\hline 6. Enthusiasm & 0.869 & 4 \\
\hline 7. Social interaction and community cohesion & 0.930 & 6 \\
\hline 8. Active participation & 0.892 & 4 \\
\hline 9. Satisfaction & 0.911 & 6 \\
\hline
\end{tabular}

Source: Calculation of the author

Thus, the model has 9 quality assurance scales with 42 characteristic variables through Cronbach's Alpha test analysis.

\section{B. EFA Analysis}

After the scale of the factors was tested for Cronbach's Alpha reliability coefficient with 42 observed variables all met the requirements, exploratory factor analysis was continued. When analyzing EFA, the authors use the Principal axis factoring extraction method with Promax rotation and the breakpoint when extracting factors with an eigenvalue greater than 1 . The scale is accepted when the Factor Loading $>0.55 ; \mathrm{O} .5 \leq \mathrm{KMO} \leq 1$; Bartlett test has Sig. $<0.05$; Cumulative $\%$ of variance $>50 \%$.

TABLE II: RESULT OF FACTORS ANALYSIS

\begin{tabular}{|l|c|c|c|c|c|c|c|c|c|}
\hline & \multicolumn{7}{|c|}{ Factors } \\
\hline & 1 & 2 & 3 & 4 & 5 & 6 & 7 & 8 & 9 \\
\hline SIE4 & 0.894 & & & & & & & & \\
\hline SIE6 & 0.893 & & & & & & & & \\
\hline SIE5 & 0.832 & & & & & & & & \\
\hline SIE1 & 0.802 & & & & & & & & \\
\hline SIE3 & 0.792 & & & & & & & & \\
\hline SIE2 & 0.781 & & & & & & & & \\
\hline SAT6 & & 0.862 & & & & & & & \\
\hline SAT4 & & 0.831 & & & & & & & \\
\hline SAT5 & & 0.803 & & & & & & & \\
\hline SAT3 & & 0.765 & & & & & & & \\
\hline SAT1 & & 0.756 & & & & & & & \\
\hline SAT2 & & 0.736 & & & & & & & \\
\hline RLG5 & & & 0.928 & & & & & & \\
\hline RLG4 & & & 0.927 & & & & & & \\
\hline RLG2 & & & 0.846 & & & & & & \\
\hline RLG1 & & & 0.738 & & & & & & \\
\hline RLG3 & & & 0.710 & & & & & & \\
\hline FWS5 & & & & 0.954 & & & & & \\
\hline FWS1 & & & & 0.845 & & & & & \\
\hline FWS2 & & & & 0.821 & & & & & \\
\hline FWS4 & & & & 0.772 & & & & & \\
\hline FWS3 & & & & 0.703 & & & & & \\
\hline PVL2 & & & & & 0.875 & & & & \\
\hline PVL4 & & & & & 0.855 & & & & \\
\hline PVL1 & & & & & 0.833 & & & & \\
\hline PVL3 & & & & & 0.707 & & & & \\
\hline SQL4 & & & & & & 0.865 & & & \\
\hline SQL2 & & & & & & 0.856 & & & \\
\hline SQL3 & & & & & & 0.850 & & & \\
\hline SQL1 & & & & & & 0.754 & & & \\
\hline ATP2 & & & & & & & 0.931 & & \\
\hline ATP4 & & & & & & & 0.829 & & \\
\hline ATP3 & & & & & & & 0.818 & & \\
\hline ATP1 & & & & & & & 0.657 & & \\
\hline RSE4 & & & & & & & & 0.897 & \\
\hline RSE2 & & & & & & & & 0.809 & \\
\hline RSE1 & & & & & & & & 0.774 & \\
\hline
\end{tabular}

\begin{tabular}{|l|l|l|l|l|l|l|l|l|l|}
\hline RSE3 & & & & & & & & 0.764 & \\
\hline ENS4 & & & & & & & & & 0.927 \\
\hline ENS2 & & & & & & & & & 0.828 \\
\hline ENS3 & & & & & & & & & 0.679 \\
\hline ENS1 & & & & & & & & 0.643 \\
\hline Sum of Cumulative \% of variance & 69.205 & \\
\hline KMO & 0.899 \\
\hline Sig.
\end{tabular}

Source: Calculation of the author.

The analysis results show that the coefficient $\mathrm{KMO}=$ 0.899 and the Barlett coefficient have the significance level $\mathrm{Sig}=0.000<0.5$, the variance extracted $69 \%$ and the variables all have factor loading coefficients greater than 0.5 .

\section{Test the Scale by CFA Method}

Confirmatory factor analysis (CFA) is the next step of exploratory factor analysis (EFA), which involves the design to independently identify, test, and adjust measurement models. The purpose of CFA is to establish well-fit measurement models that can be used to test structural equation models.

The results of CFA have Chi-squares/df $=2.063$; GFI $=0.850 ; \quad$ TLI $=0.928 ; \quad$ CFI $=0.935 ; \quad$ RMSEA $=0.05$. However, the GFI $=0.85<0.9$ is known to be sample dependent [32] but still acceptable as suggested by Baumgartner et al. (1996) [33] Thereby, it can be shown that the scale model of factors affecting the satisfaction of people is consistent with market data. The results show that the factors all meet the requirements for reliability and are presented in Table III below.

\begin{tabular}{|c|c|c|c|c|}
\hline \multirow{2}{*}{$\begin{array}{l}\text { Observed } \\
\text { variables }\end{array}$} & \multicolumn{3}{|c|}{ Reliability } & \multirow[t]{2}{*}{ Value } \\
\hline & CR & AVE & MSV & \\
\hline RSE & 0.892 & 0.675 & 0.252 & \multirow{9}{*}{ Qualified } \\
\hline SIE & 0.931 & 0.692 & 0.120 & \\
\hline SAT & 0.912 & 0.632 & 0.147 & \\
\hline FWS & 0.920 & 0.697 & 0.252 & \\
\hline RLG & 0.924 & 0.710 & 0.188 & \\
\hline ATP & 0.894 & 0.679 & 0.187 & \\
\hline PVL & 0.899 & 0.690 & 0.362 & \\
\hline SQL & 0.900 & 0.692 & 0.125 & \\
\hline ENS & 0.873 & 0.634 & 0.362 & \\
\hline
\end{tabular}

\section{Test the Model by SEM}

To test the proposed hypotheses, the study uses SEM. SEM results show that the theoretical model is accepted, with Chi-squares/df=2.437; GFI=0.823; TLI=0.903; $\mathrm{CFI}=0.909$; RMSEA $=0.059$. Although GFI $=0.823$ is not as high as the recommended level of 0.9 , it is still acceptable as suggested by Baumgartner et al. (1996) [33].

TABLE IV: RESULtS OF TESTING THE CAUSAL RELATIONSHIP BETWEEN CONCEPTS IN THE FORMAL THEORETICAL MODEL

\begin{tabular}{|l|l|l|l|l|l|l|l|}
\hline & & & Estimate & S.E. & C.R. & P & Label \\
\hline SQL & $<---$ & RSE & .223 & .055 & 4.027 & $* * *$ & \\
\hline PVL & $<---$ & SQL & .137 & .057 & 2.399 & .016 & \\
\hline PVL & $<---$ & RSE & .221 & .059 & 3.744 & $* * *$ & \\
\hline SAT & $<---$ & FWS & .347 & .061 & 5.717 & $* * *$ & \\
\hline SAT & $<---$ & PVL & .116 & .056 & 2.075 & .038 & \\
\hline SAT & $<---$ & RLG & .165 & .066 & 2.513 & .012 & \\
\hline ENS & $<---$ & SAT & .343 & .050 & 6.811 & $* * *$ & \\
\hline SIE & $<---$ & SAT & .175 & .039 & 4.536 & $* * *$ & \\
\hline ATP & $<---$ & SAT & .293 & .055 & 5.299 & $* * *$ & \\
\hline
\end{tabular}

Source: Calculation of the author. Note: $* * *(\mathrm{P}<0.001)$. 


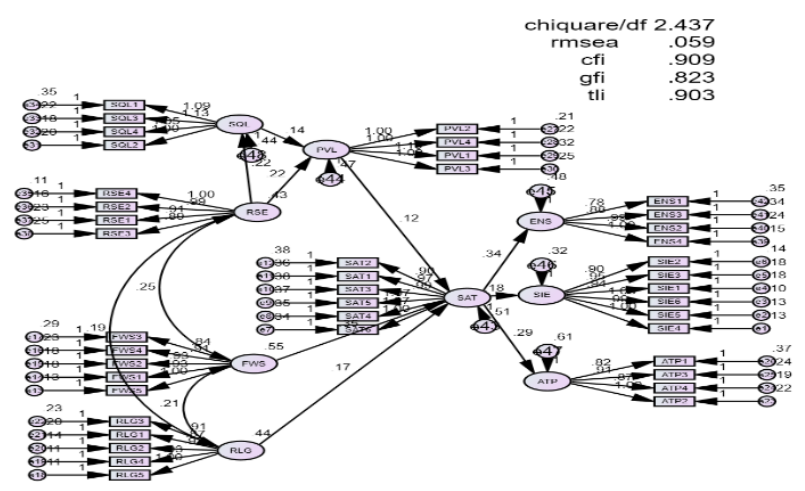

Fig. 3. Results of SEM. Source: Calculation of the author.

Thus, the variables: Expectations residents; quality of service; perceived value; waste classification facilities; Responsibility of Local government have a positive correlation with and statistically significant impact on satisfaction; When the community is satisfied with the waste categorizing activities, it will create enthusiasm, active participation and social interaction - community cohesion in the waste classification. Therefore, the above test results show that this study provides empirical evidence to confirm and supplement the integrated model of satisfaction theories based on the proposal of Wang et al. (2020) [8].

\section{DISCUSSION}

H1 Expectations residents can improve the service quality of household waste classification. The expectation of people is a type of belief before a performance of a good or service [15]. This result is also confirmed by Odonkor et al. (2020) [10], Wang et al. (2020) [8] as it is said that the waste classification facilities or the quality of waste treatment services in the community meet the expectation of people.

$\mathrm{H} 2$ Expectation of residents can enhance the perceived value of household waste classification. The results of the qualitative research also show that the people in the survey area expect the waste classification facilities or the quality of waste treatment services in the community to impact the perceptions that garbage sorting can reduce environmental pollution and it is a very practical activity.

The research results show that $\mathrm{H} 3$ and $\mathrm{H} 4$ confirm that there is a positive influence of service quality on Perceived value and Perceived Value on Satisfaction in classifying domestic waste. This is consistent with Tarn (1999) [19] that perceived value is related to quality and satisfaction. In addition, perceived value is considered as the main determinant of satisfaction of customers [20], [21].

H5. Waste classification facilities are the factor that has the strongest impact on the satisfaction of people in categorizing waste. This is consistent with Doberl et al. (2002) [23] and Khan et al. (2012) [24] that the level of government investment in waste treatment significantly affects the satisfaction of people from the implementation of household waste treatment. Koo et al. (2009) [25] and Chu et al. (2021) [17] showed that the arrangement and deployment of garbage bins and other waste disposal facilities also affected the satisfaction of residents from waste management efficiency. This result is also consistent with the survey of households in Hai Chau district, all of which said that the arrangement of garbage bins, reasonable classification as well as the frequency of collecting waste by trucks have most meaningful to waste classification of people.

H6. Satisfaction from household waste classification increases if the Responsibility of the Local Government increases. In recent years, the content of domestic waste management has been a top concern of the government. Besides construction activities, strengthening environmental waste management agencies, or investing in physical facilities, the City government is always at the forefront of movements to classify plastic waste such as saying no to plastic bottles, instead of using glass bottles in their offices [34]. Moreover, the City has promptly issued guiding documents related to waste classification. Over time, propaganda and education on the mass media such as DRT, Da Nang newspaper, ..., or having meetings of residential blocks for reference and discussion in activities of waste sorting have made a significant contribution to the environmental quality. This clearly shows the responsibility of the city in social management in general and environmental management in particular [17]. Thus, this has created more trust, satisfaction, and support of the people with the movements proposed by the city.

Research results of $\mathrm{H} 7$ and $\mathrm{H} 9$ show that Satisfaction enhances enthusiasm and improves active participation in household waste classification. This result is also consistent with Wang et al. (2020) [8] when it is suggested that once the community is satisfied with the waste classifying activity, or with the environmental results, the community will be enthusiastic in the waste classification. In addition, Satisfaction improves active participation in household waste classification.

H8 Satisfaction enhances social interaction and community cohesion in domestic waste classification. This result is also consistent with Wang et al. (2020) [8]. At the same time, this research using content analysis in in-depth interviews also shows that when the community is satisfied with the garbage sorting, it will help them to participate more in the waste classifying with others. In addition, when there are movements, neighbors have the opportunity to open and talk, to be more friendly, and sometimes also receive a lot of support and help from surrounding neighbors when facing difficulties.

\section{IMPLICATION}

Firstly, the discovery shows that people are satisfied with waste classification facilities. Thus, the city government needs to increase investment, arrangement, and deployment of garbage bins and waste treatment vehicles [25]. At the same time, it is necessary to maintain a reasonable waste-of collecting time.

Secondly, it is necessary to propagate to raise public awareness in residential areas about the benefits of waste classification at source as well as the harms of environmental pollution to strengthen the cooperation of residents on waste treatment [35] through mass media such as DRT Da Nang, Da Nang newspaper.

Thirdly, the above analysis results show that, when people are satisfied with the waste classification movement 
proposed by the government, it makes them enthusiastic and actively participate in the household waste classification, as well as helps them connect more with each other in the community. That shows, the government needs to improve its responsibilities in social management in general and environmental management in particular to create more trust, satisfaction, and support of the people with the movement proposed by the city.

Fourth, strengthening regulations and enforcement of laws and regulations related to waste management can increase satisfaction.

Fifth, programs such as: "Fighting plastic waste", "Say no to single-use plastic bags and plastic products", "Shopping with less plastic bag", "Use a pair of cages to buy food", or "Hand out eco-bags to go to the market", "categorizing waste at source", ... should be implemented consistently, continuously and with the participation of communities such as women's unions, farmers, youth union, ..., to reduce waste, contribute to environmental protection.

Sixth, to take the satisfaction index of people as a measure to evaluate the effectiveness of state management, the government needs to regularly survey the satisfaction of people through methods such as: Distributing survey questionnaires via mailboxes, evaluating through the government's website system. Thereby, first of all, it will help people to show their ownership, which is a subject in accessing state management activities. Additionally, it will help the municipal government to early recognize the limitations, results and propose new orientations and new goals to improve the state management of the environment.

\section{CONCLUSIONS}

Waste classification at source is an important content in the environmental management of Hai Chau district in recent years and has attracted the attention of the community. Many studies also confirm that the satisfaction of people is a measure of the quality of environmental management. Therefore, this study was conducted to assess the satisfaction of the people that is appropriate for the above context. The analysis results show that waste classification facilities are the factor that has the strongest impact on the satisfaction of people in classifying waste. Expectations of residents, service quality, and perceived value have a positive influence on satisfaction in classifying domestic waste. In addition, this study also found that the responsibility of the local government, that has been shown in recent years, from paying attention to and strengthening the environmental waste management agency or investing in physical facilities, has created more trust, satisfaction, and support of the people with the movement of sorting waste at source. According to the above results, it also shows that the environmental results have created the enthusiasm and active participation of the community in categorizing waste.

The present study provides new evidence to confirm that the state management of the environment of the city in recent years has been effective and practical, thereby, this research contributes a theory part and provides some implications for managers, citizens, and further research in the future.

\section{CONFLICT OF INTEREST}

The authors declare no conflict of interest.

\section{AUTHOR CONTRIBUTION}

All authors participated equally in designing and estimation current research. However, Nguyen Van Thanh writes the abstract, introduction and conclusion; Dang Thanh Le writes the analytical framework and hypotheses; Luong Tinh runs the model and analyzes the results. All authors approve the final version.

\section{REFERENCES}

[1] S. D. Mancini, A. R. Nogueira, D. A. Kagohara, J. A. S. Schwartzman and T. Mattos, "Recycling potential of urban solid waste destined for sanitary landfills: The case of Indaiatuba, SP, Brazil," Waste Management \& Research, vol. 25, no. 6, pp. 517-523, 2007.

[2] A. A. Babaei, N. Alavi, G. Goudarzi, P. Teymouri, K. Ahmadi, and M. Rafiee, "Household recycling knowledge, attitudes and practices towards solid waste management," Resources, Conservation and Recycling, vol. 102, pp. 94-100, 2015.

[3] T. Binh. (2021). Strengthen the management and prevention of littering plastic waste. [Online]. Available: https://danang.gov.vn/chi-tiet?id=44491\&_c =100000150,3,9

[4] X. Liu, Z. Wang, W. Li, G. Li, and Y. Zhang, "Mechanisms of public education influencing waste classification willingness of urban residents," Resources, Conservation and Recycling, vol. 149, pp. 381-390, 2019.

[5] B. Rahardyan, T. Matsuto, Y. Kakuta, and N. Tanaka, "Resident's concerns and attitudes towards solid waste management facilities," Waste Management, vol. 24, no. 5, pp. 437-451, 2004.

[6] D. Raje, P. Wakhare, A. Deshpande, and A. Bhide, "An approach to assess level of satisfaction of the residents in relation to SWM system,' Waste Management \& Research, vol. 19, no. 1, pp. 12-19, 2001.

[7] D. Houghton, "Resident satisfaction in an Australian new town: Kwinana, Western Australia," Australian Journal of Social Issues, vol. 11 , no. 4, pp. 263-275, 1976.

[8] Q. Wang, X. Long, L. Li, L. Kong, X. Zhu, and H. Liang, "Engagement factors for waste sorting in China: The mediating effect of satisfaction," Journal of Cleaner Production, vol. 267, p. 122046 , 2020 .

[9] M. Abas et al., "Public satisfaction and willingness to pay (WTP) for better solid waste management services in rural area of Kelantan, Malaysia," IOP Conference Series: Earth and Environmental Science, 2021, vol. 756, no. 1, p. 012083, IOP Publishing.

[10] S. T. Odonkor, K. Frimpong, and N. Kurantin, "An assessment of house-hold solid waste management in a large Ghanaian district," Heliyon, vol. 6, no. 1, p. e03040, 2020.

[11] Y. Fetene, "Client satisfaction towards municipal solid waste management service in Jimma city, South West Ethiopia," International Journal of Environmental Sciences \& Natural Resources, vol. 13 , no. 3 , pp. 81-86, 2018.

[12] N. Cohen, S. Mizrahi, and E. Vigoda-Gadot, "Alternative provision of public health care: the role of citizens' satisfaction with public services and the social responsibility of government," Health Economics, Policy and Law, pp. 1-20, 2020.

[13] R. L. Oliver, "A cognitive model of the antecedents and consequences of satisfaction decisions," Journal of Marketing Research, vol. 17, no. 4, pp. 460-469, 1980.

[14] P. A. Dabholkar, C. D. Shepherd, and D. I. Thorpe, “A comprehensive framework for service quality: an investigation of critical conceptual and measurement issues through a longitudinal study," Journal of Retailing, vol. 76, no. 2, pp. 139-173, 2000 .

[15] J. C. Olson and P. A. Dover, "Disconfirmation of consumer expectations through product trial," Journal of Applied Psychology, vol. 64, no. 2, p. 179,1979

[16] T. F. Khanom, T. Farjana, A. Mamun, A. Hossain, and A. Baten, "Household satisfaction on solid waste collection services conducted by NGOs in Mymensingh Municipality, Bangladesh," International Journal of Natural and Social Sciences, vol. 2, no. 4, pp. 14-22, 2015.

[17] X. Chu et al., "The influencing factors of Harbin (China) residents' satisfaction with municipal solid waste treatment," Waste Management \& Research, vol. 39, no. 1, pp. 83-92, 2021. 
[18] Y.-C. Chen, "Effects of urbanization on municipal solid waste composition," Waste Management, vol. 79, pp. 828-836, 2018.

[19] J. L. Tarn, "The effects of service quality, perceived value and customer satisfaction on behavioral intentions," Journal of Hospitality \& Leisure Marketing, vol. 6, no. 4, pp. 31-43, 1999.

[20] G. H. McDougall and T. Levesque, "Customer satisfaction with services: Putting perceived value into the equation," Journal of Services Marketing, 2000.

[21] I. A. Wong and V. H. Fong, "Examining casino service quality in the Asian Las Vegas: An alternative approach," Journal of Hospitality Marketing \& Management, vol. 19, no. 8, pp. 842-865, 2010.

[22] V. A. Zeithaml, "Consumer perceptions of price, quality, and value: a means-end model and synthesis of evidence," Journal of Marketing, vol. 52, no. 3, pp. 2-22, 1988.

[23] G. Döberl et al., "Long-term assessment of waste management options-a new, integrated and goal-oriented approach," Waste Management \& Research, vol. 20, no. 4, pp. 311-327, 2002.

[24] S. Khan and I. Farooqi, "Prioritising municipal solid waste management factors in India using fuzzy analytic hierarchy process," International Journal of Environment and Waste Management, vol. 10, no. 4, pp. 423-440, 2012.

[25] J. Koo, M.-Y. Kang, Y.-C. Seo, J.-K. Sun, B. Yoon, and B.-H. Kim, "An Analysis of Local Government's Intentions for Privatization Policy of Waste Treatment Facilities in Korea," Journal of Environmental Impact Assessment, vol. 18, no. 5, pp. 257-270, 2009.

[26] G. Simmel, On Individuality and Social Forms, University of Chicago Press Chicago, 1971.

[27] R. K. Merton, "The unanticipated consequences of purposive social action," American Sociological Review, vol. 1, no. 6, pp. 894-904, 1936.

[28] S. D. Vivek, S. E. Beatty, V. Dalela, and R. M. Morgan, "A generalized multidimensional scale for measuring customer engagement," Journal of Marketing Theory and Practice, vol. 22, no. 4, pp. 401-420, 2014.

[29] J. Hair, R. Anderson, B. Babin, and W. Black, Multivariate Data Analysis: A Global Perspective, Pearson Upper Saddle River, NJ, 2010.

[30] J. C. Anderson and D. W. Gerbing, "Structural equation modeling in practice: A review and recommended two-step approach," Psychological Bulletin, vol. 103, no. 3, p. 411, 1988.

[31] J. C. Nunnally, Psychometric Theory, 2nd ed, Mcgraw hill book company, 1978.

[32] S. A. Mulaik, L. R. James, J. Van Alstine, N. Bennett, S. Lind, and C. D. Stilwell, "Evaluation of goodness-of-fit indices for structural equation models," Psychological Bulletin, vol. 105, no. 3, p. 430, 1989.

[33] H. Baumgartner and C. Homburg, "Applications of structural equation modeling in marketing and consumer research: A review," International journal of Research in Marketing, vol. 13, no. 2, pp. 139-161, 1996.

[34] K. Hong. (2019). Da Nang will not use plastic bottles in meetings. [Online]. https://dantri.com.vn/xa-hoi/da-nang-khong-su-dung-chai-nhua-trongcac-cuoc-hop-20190424180033717.htm

[35] T. Evison and A. D. Read, "Local Authority recycling and waste-awareness publicity/promotion," Resources, Conservation and Recycling, vol. 32, no. 3-4, pp. 275-291, 2001.

Copyright $(2022$ by the authors. This is an open access article distributed under the Creative Commons Attribution License which permits unrestricted use, distribution, and reproduction in any medium, provided the original work is properly cited (CC BY 4.0).

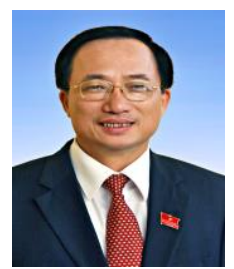

Nguyen Van Thanh was born in 1957. He received a degree in industrial economics from Hanoi University of Science and Technology (1994), master of industrial economics from Hanoi University of Science and Technology (1998), doctor of economics from Hanoi University of Science and Technology (2005), Assoc. Prof. of Economics from Hanoi University of Science and Technology (2016). He is currently the vice chairman of the Central Theoretical Council of the Communist Party of Vietnam; Member of the Scientific Council of the Institute of Marine Environment and Resources, Member of the International Society of Systems Science (ISSS); International Federation of Systems (IFSR), one of the 21 founders of World Council on City Data (WCCD) - ISO-37120. His current research interests include: Smart city development; Building ecological urban areas; ECO2 economy; Circular economy; Sustainable development.

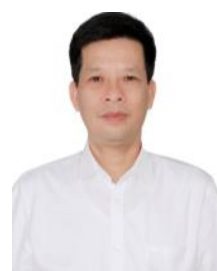

Dang Thanh Le was born in 1969. He received a degree in electronic engineering in 1990, a bachelor degree in foreign trade economics in 1995, a master degree in business administration in 1998, and a doctoral degree in organization and production management in 2004 from Hanoi University of Science and Technology, Vietnam. He is currently the director, Institute of Administrative Studies - National Academy of Public Administration. His current research interests include: Managing economic growth by improving environmental quality; Policy on smart city development; Environmental policy and sustainable development; Policies to support the development of small and medium enterprises.

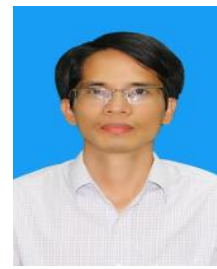

Luong Tinh was born in 1983. He received a bachelor degree in economics in 2008, a master degree in development economics in 2012, a PhD in development economics in 2019. He is currently a researcher at the Central Institute of Social Sciences of the Central Region - Vietnam Academy of Social Sciences. His current research interests include: Behavior of people towards green consumption; behavior of farmers in green production; Waste management; and Sustainable development. 